\title{
MICROSTRUCTURAL AND MECHANICAL STUDY OF INCONEL 625 - TUNGSTEN CARBIDE COMPOSITE COATINGS OBTAINED BY POWDER LASER CLADDING
}

\begin{abstract}
This study focuses on the investigation of fine $(\sim 0.54 \mu \mathrm{m})$ tungsten carbide particles effect on structural and mechanical properties of laser cladded Inconel 625-WC composite. Three powder mixtures with different Inconel 625 - WC weight ratio (10,20 and 30 weight $\%$ of WC) were prepared. Coatings were made using following process parameters: laser beam diameter $\varnothing \approx 500 \mu \mathrm{m}$, powder feeder rotation speed $-7 \mathrm{~m} / \mathrm{min}$, scanning velocity $-10 \mathrm{~m} / \mathrm{min}$, laser power $-220 \mathrm{~W}$ changed to $320 \mathrm{~W}$, distance between tracks $-1 \mathrm{~mm}$ changed to $0.8 \mathrm{~mm}$. Microstructure and hardness were investigated. Coatings produced by laser cladding were crack and pore free, chemically and structurally homogenous. High cooling rate during cladding process resulted in fine microstructure of material. Hardness improved with addition of WC from $396.3 \pm 10.5 \mathrm{HV}$ for pure Inconel 625 , to $469.9 \pm 24.9 \mathrm{HV}$ for 30 weight $\%$ of WC. Tungsten carbide dissolved in Inconel 625 which allowed formation of intergranular eutectic that contains TCP phases.

Keywords: Laser cladding, Inconel 625, Tungsten Carbide, Metal Matrix Composites, Rapid prototyping
\end{abstract}

\section{Introduction}

Nickel-based superalloys such as Inconel 625 are widely used as material for high temperature applications because of their resistance to thermally and chemically aggressive environment: especially as heat exchangers, in aerospace industry, chemical industry, power generation plants, turbines etc. [1]. Originally, superalloys were used in gas turbines as a material that could replace previously used steels. Because of the specific properties of nickel, such as high toughness and ductility, it was the metal of choice for the base of alloys [17]. Due to the chemical composition and specific properties of Inconel 625 (Table 1), such as its ability to retain high mechanical strength, very good wear and oxidation resistance in high temperatures (up to $\approx 650^{\circ} \mathrm{C}$ ), it is widely used in both energy and aerospace industry as a material for machine elements $[2,18]$. Despite good mechanical properties of pure Inconel 625 alloy, it is desired to improve its wear resistance in order to prolong service life of machine parts which are partially damaged during work. The economic aspect is an important factor in present world, where even a small improvement supported by the possibility of reducing costs is valuable. Improving mechanical properties of Inconel 625 material could reduce the demand of resources needed to produce both energy and mechanical parts.

Improving mechanical properties of materials by producing protective coatings are cost - efficient methods that lead to better hardness and wear resistance with relatively low cost.
TABLE 1

Typical properties of Inconel 625 [20]

\begin{tabular}{|c|c|}
\hline \hline \multicolumn{2}{|c|}{ INCONEL 625 } \\
\hline Property & Value \\
\hline Density & $8,44 \mathrm{~g} / \mathrm{cm}^{3}$ \\
\hline Melting Point & $1350^{\circ} \mathrm{C}$ \\
\hline Coefficient of thermal expansion & $12,8 \mu \mathrm{m} / \mathrm{m}^{\circ} \mathrm{C}\left(20-100^{\circ} \mathrm{C}\right)$ \\
\hline Rigidity modulus & $79 \mathrm{kN} / \mathrm{mm}^{2}$ \\
\hline Elasticity modulus & $205,8 \mathrm{kN} / \mathrm{mm}^{2}$ \\
\hline
\end{tabular}

Some recently developed techniques can be used to combine 2 solid substrates into another material with better properties. Tungsten arc alloying of niobium aluminide coating which is resistant to oxidation in high temperatures quite recently developed technique [13]. Other materials, such as steel can have its properties improved by initiating reaction with gas to make thin protective layer [14]. Metal Matrix Composites (MMC) are materials that combine properties of metal matrix and reinforcement material. Metals characterised by plasticity and weldability can be modified by means of the addition of mostly ceramic or polymer particles. Because of good wettability of carbides, nickel based superalloys are extremely potent as matrix material. Tungsten carbide combines typical ceramic properties such as high hardness and wear resistance [3]. Inconel 625-WC MMC materials were investigated here. The main aim behind using Inconel 625-WC composite is to achieve optimal mechanical and corrosion resistant performance. In order to improve wear resist-

\footnotetext{
* AGH UNIVERSITY OF SCIENCE AND TECHNOLOGY, FACULTY OF MATERIALS SCIENCE AND CERAMICS, KRAKOW, POLAND

** AGH UNIVERSITY OF SCIENCE AND TECHNOLOGY, FACULTY OF METALS ENGINEERING AND INDUSTRIAL COMPUTER SCIENCE, KRAKOW, POLAND

\# Corresponding author: huebnerj@agh.edu.pl
} 
ance various hardfacing techniques, such as plasma spraying, thermal spraying, pulsed plasma arc deposition or arc welding were proposed $[4,5]$. Previously mentioned conventional methods have their disadvantages. The main problem is the porosity of deposited layers and bonding between coating and substrate surface. The other problem involves high temperature during deposition process. Because of WC low free formation enthalpy of $38.5 \mathrm{~kJ} / \mathrm{mol}$ it dissolves easily in Inconel $625[3,4]$.

Recent years showed a considerable rise of interest in rapid prototyping as the common method to obtain $2 \mathrm{D}$ and $3 \mathrm{D}$ objects from broad spectrum of materials. Variety of techniques allows producing large amount of different shape, from complicated objects to protective coatings. Some research were focused on producing mechanically resistant coatings by reaction of substrate surface with feeded material [15]. Laser cladding is an universal additive manufacturing technique that allows to produce geometrically complicated machine elements of high quality or coatings $[6,19]$. This technique developed greatly during the last fifteen years allowing to avoid disadvantages of conventional methods. Choosing optimal parameters of laser cladding process leads to greater control of final properties. Changing process parameters allows to design a material that is able to meet strict requirements [20]. In laser cladding, previously prepared material, in form of powder or wire, is applied directly under the laser beam. Because of high energy density, the material rapidly melts in form of elliptical melt pool. As the laser beam moves forward, material crystallises and welds by diffusion to substrate surface. The properly deposited material is homogenous, crack-free with good bonding to substrate $[20,21]$.

\section{Experimental}

\subsection{Samples preparation}

Commercially produced powders of cast Inconel 625 (Table 2) - average grain size of $104 \mu \mathrm{m}$, angular shape, and tungsten carbide - average grain size of $0.54 \mu \mathrm{m}$, were mixed together. Three different Inconel $625-\mathrm{WC}$ wt \% proportions were prepared: 10,20 and $30 \mathrm{wt} \%$ of WC. In order to homogenize $100 \mathrm{~g}$ of each powder mixture, they were put inside milling chamber with $100 \mathrm{~g}$ of cemented carbides grinding balls - weight ratio $1: 1$ and $100 \mathrm{ml}$ of isopropyl alcohol. Additionally $0,025 \mathrm{~g}$ of resin were added to improve WC powder adhesion to Inconel 625. Powders were homogenized for 90 minutes in ball mill. Total number of 3 different powder mixtures and pure Inconel 625, as reference material, were prepared for further processing.

Material used as substrate surface for laser cladding was previously prepared Inconel 625 overlays obtained by the Cold Metal Transfer (CMT) technique adapted and described in detail by Kusiński [7]. It was chosen because of the similar chemical composition of used Inconel 625 powder. In used CMT technique, Inconel 625 coating was deposited on rotating steel $16 \mathrm{Mo} 3$ pipe (inner diameter $\varnothing=80 \mathrm{~mm}$, steel thickness $=5 \mathrm{~mm}$ ) by applying electrical current $\mathrm{I}=200 \mathrm{~A}$ and voltage $\mathrm{V}=20 \mathrm{~V}$, to Inconel 625 wire in argon atmosphere. Obtained Inconel 625 coating had thickness about $2.5 \mathrm{~mm}$. After CMT process, pipe was partially polished to provide flat surfaces. Then it was cut into rings and further into rectangular pieces of side length $\mathrm{a} \approx 20 \mathrm{~mm}$. The prepared pieces were cleaned in ultrasonic cleaner in isopropanol to remove grease and pollution from surface.

The prepared powders were put inside powder feeder connected to laser head. Laser cladding, using JK2000FL ytterbium dopped wire fibre laser with wavelength of $1063 \mathrm{~nm}$, was performed on previously prepared Inconel 625 pieces. During laser cladding process, powders were transported by argon, from powder feeder to the nozzles in laser cladding head. Then powders were dusted directly on the substrate surface. Because of high energy density of laser beam, powders melted instantaneously which resulted in appearance of melt pool. As the process progressed and laser cladding head moved forward, deposited material solidified while became welded to the substrate surface. Schematic illustration of the process is shown in Fig. 1.

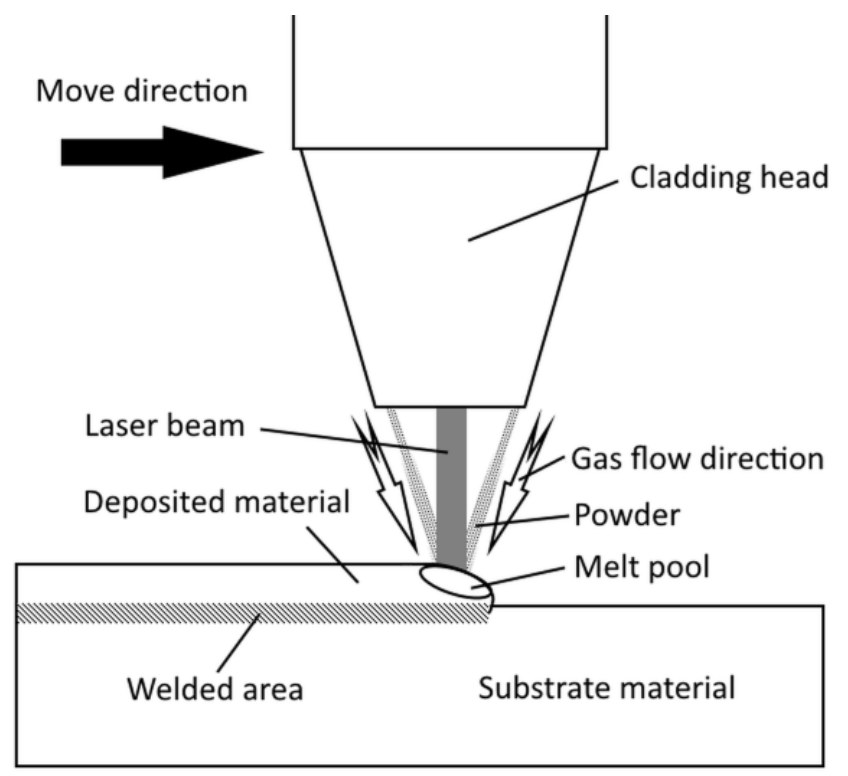

Fig. 1. Schematic illustration of laser cladding process

The following process parameters were used. Laser beam diameter $\varnothing \approx 500 \mu \mathrm{m}$. Initial process parameters: laser power $220 \mathrm{~W}$, distance between the centre of the tracks $-1 \mathrm{~mm}$, were

TABLE 2

Chemical composition of Inconel 625 in weight \% [20]

\begin{tabular}{|c|c|c|c|c|c|c|c|c|c|c|c|c|c|c|}
\hline $\mathbf{N i}$ & $\mathrm{Cr}$ & Mo & $\mathbf{N b}$ & $\mathbf{F e}$ & $\mathrm{C}$ & Mn & $\mathrm{Si}$ & $\mathbf{P}$ & S & Al & $\mathbf{T i}$ & Co & Ta & $\mathbf{C u}$ \\
\hline $\begin{array}{l}\text { Min } \\
58.0\end{array}$ & $\begin{array}{c}20.0- \\
23.0\end{array}$ & $\begin{array}{l}8.0- \\
10.0\end{array}$ & $\begin{array}{c}3.15- \\
4.15\end{array}$ & $\begin{array}{c}\text { Max } \\
5.0\end{array}$ & $\begin{array}{c}\mathrm{Max} \\
0.1\end{array}$ & $\begin{array}{c}\mathrm{Max} \\
0.5\end{array}$ & $\begin{array}{c}\text { Max } \\
0.5\end{array}$ & $\begin{array}{c}\text { Max } \\
0.015\end{array}$ & $\begin{array}{c}\text { Max } \\
0.015\end{array}$ & $\begin{array}{c}\mathrm{Max} \\
0.4\end{array}$ & $\begin{array}{c}\mathrm{Max} \\
0.4\end{array}$ & $\begin{array}{c}\text { Max } \\
1.0\end{array}$ & $\begin{array}{l}\text { Max } \\
0.05\end{array}$ & $\begin{array}{c}\text { Max } \\
0.5\end{array}$ \\
\hline
\end{tabular}


changed to: laser power- $320 \mathrm{~W}$, distance between centre of the tracks $-0.8 \mathrm{~mm}$, in order to produce homogenous, crack-free coating. Powder feeder rotation speed was set to $7 \mathrm{~m} / \mathrm{min}$ and traverse speed was set to $10 \mathrm{~m} / \mathrm{min}$. Coatings were deposited by making 10 parallel tracks (length $10 \mathrm{~mm}$ ). The total amount of 6 sublayers in one track were made on each sample. Surface of coatings was remelted by defocused laser beam in order to reduce roughness. Effects were observed using light microscopy. Total number of 6 different types of samples were prepared after adjusting process parameters (Table 3 ). Temperature of melt pool during laser action was reaching maximum of about $1750^{\circ} \mathrm{C}$.

TABLE 3

Types of prepared samples

\begin{tabular}{|c|c|c|c|}
\hline $\begin{array}{c}\text { Sample } \\
\text { type }\end{array}$ & WC [wt \%] & $\begin{array}{c}\text { Laser Power } \\
\text { [W] }\end{array}$ & $\begin{array}{c}\text { Distance between } \\
\text { tracks [mm] }\end{array}$ \\
\hline Reference & - & 320 & 0.8 \\
\hline IW1 & 10 & 220 & 1 \\
\hline IW2 & 10 & 220 & 0.8 \\
\hline IW3 & 10 & 320 & 0.8 \\
\hline IW4 & 20 & 320 & 0.8 \\
\hline IW5 & 30 & 320 & 0.8 \\
\hline
\end{tabular}

\subsection{Methods}

All of the samples were cut parallelly and perpendicularly to track. After polishing, cross-sections were electrochemically etched in $10 \% \mathrm{CrO}_{3}$ water solution. The hardness tests were performed on samples using Future-Tech FM-700 Hardness tester with Vickers indenter. Samples were tested under load of 200 $\mathrm{g}$ for 15 seconds. Total number of measurements are different for each sample because of slightly different thickness of coatings. Additionally, nanohardness test was performed on samples containing $30 \mathrm{wt} . \%$ of WC in order to investigate hardness of different phases that appeared in the samples, using CSM instruments diamond Berkovich nanoindenter under load of $30 \mathrm{mN}$. Microstructure of samples was examined by Leica DM2500M optical microscope and NOVA NANO SEM 200 equipped with EDAX EDS analyzer. EDS analysis was performed on samples, powders and powder mixtures to confirm elemental composition of material and possible impurities. Phase composition of powders and deposited coatings were investigated by using PANalitycal X-ray Diffractor (XRD) and X-pert HighScore software.

\section{Results and Discussion}

\subsection{Powder mixtures preparation}

Powders before and after homogenisation were examined using SEM. As shown in Fig. 2A, Inconel 625 powder appears mainly in form of spheres with small number of partially deformed grains. Tungsten carbide powder showed tendency to agglomerate because of small grain size (Fig. 2B). During homogenisation, WC agglomerates were strongly colliding with Inconel 625 which resulted in covered Inconel 625 surface. Because of high intensiveness of homogenisation in rotary vibrating mill, some deformations in Inconel 625 particles were observed. High plasticity of superalloy, resulted in more angular form than before the process (Fig. 2C). Uniform coating of fine WC powder can be seen on Inconel 625 surface. The EDS analysis confirmed that some of the hard WC grains were mechanically injected into the softer Inconel 625 surface.
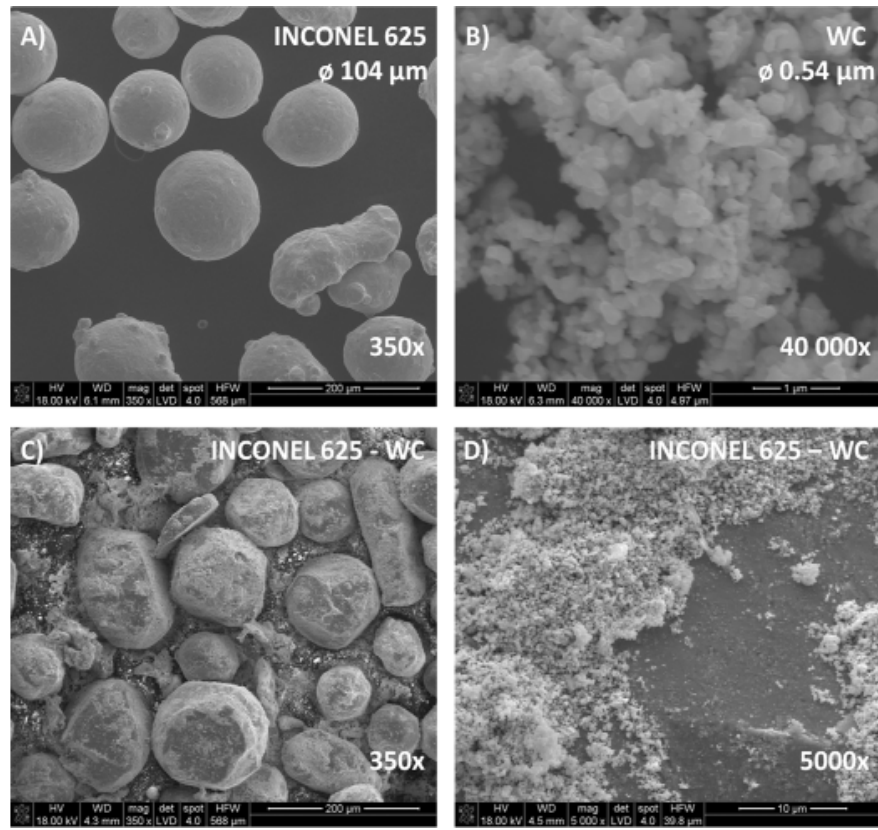

Fig. 2. SEM images showing: A - Inconel 625 powder; B - WC powder; C, D - Inconel 625 - WC mixture after 90 minutes of homogenisation

\subsection{Inconel 625 - WC coatings}

\subsubsection{Light microscopy}

Fig. 3A showed typical surface of the coating which was deposited by us using the laser cladding. The effect of remelting that was performed to reduce roughness of surface was observed. During laser cladding process, some powder that were fed onto the surface rebound from it and scatter in every direction. This happens because of high powder velocity after leaving a nozzle. When laser beam moves further, that powder landed on a surface that was still hot and partially melted into the clad. After cooling it appeared as a small bulks that increase roughness of surface.

As shown in Fig. 3B initial process parameters of laser power $220 \mathrm{~W}$ and distance between centre of the tracks of $1 \mathrm{~mm}$, did not allow to obtain homogenous and crack free coatings. The proposed distance between center of the tracks resulted in big cracks between them. Tracks geometrical dimensions were measured. Average tracks width was $925 \mu \mathrm{m}$ and thickness was $1556 \mu \mathrm{m}$. The partially melted powder can be observed inside these cracks. The surface of coating was not flat. Central area of tracks was elevated higher than their side area. Boundary between deposited material and substrate showed that Inconel 
625-WC were embedded into the surface. Examination of microstructure inside the tracks shows that it is fine and pore and delamination free. Additionally, heat affected zones can be observed for each consequent layer.
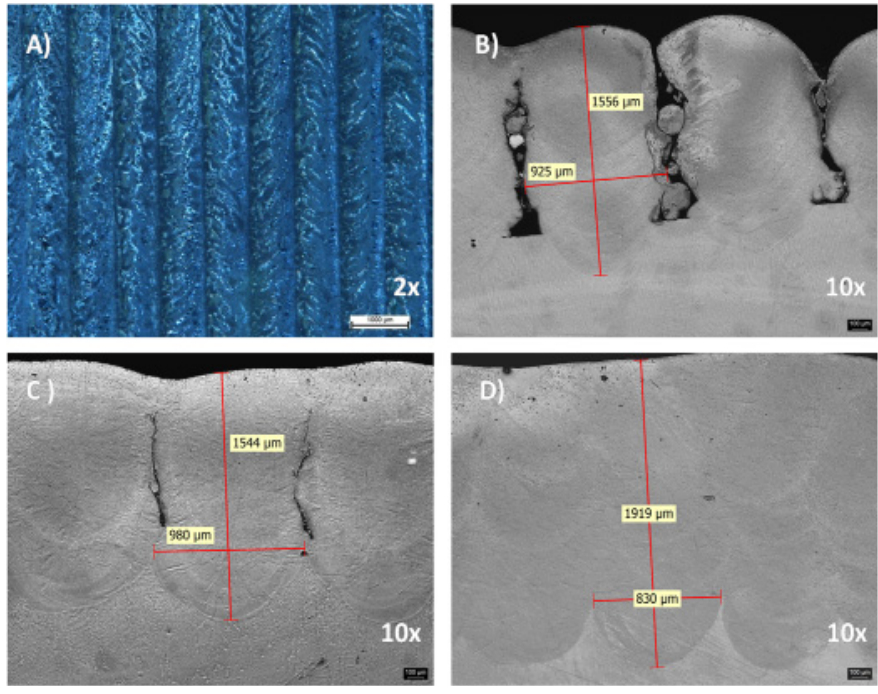

Fig. 3. Light microscopy images showing effect of process parameter change on microstructure: A - surface after remelting; B $-220 \mathrm{~W}, 1$ $\mathrm{mm} ; \mathrm{C}-320 \mathrm{~W}, 1 \mathrm{~mm}$; D $-320 \mathrm{~W}, 0.8 \mathrm{~mm}$

Increasing laser power to $320 \mathrm{~W}$ resulted in the decreasing of cracks size between tracks as seen on Fig. 3C. Thickness of coating was $1544 \mu \mathrm{m}$ while track width changed to $980 \mu \mathrm{m}$. Previously observed powder particles inside cracks were melted due to increased laser power. Surface of the coating was more flat than for a sample prepared with laser power of $220 \mathrm{~W}$. In the case of this sample, heat affected zones were more easy to observe. Boundary between substrate and coating showed a difference in microstructure despite the use of same material.

As seen in Fig. 3D reduction of distance between center of the tracks from $1 \mathrm{~mm}$ to $0.8 \mathrm{~mm}$ allowed to obtain completely crack and pore-free coating. Thickness of tracks was $1919 \mu \mathrm{m}$ and width was $830 \mu \mathrm{m}$. Microstructure of deposited material was homogenous and uniform. However, some porosity was noticed in the surface of the coating near its surface. The roughness of the coating surface had no significant cavities. The observation of microstructure shown that the heat affected zones were visible for each layer of material.

The examination of the process parameter adjustment effect showed that uniform and crack-free coating can be obtained while tracks are overlapping each other. This prevents formation of cracks which could be dangerous because of increased risk of corrosion which is the main reason for producing such layers. Reduction of distance between center of tracks and increasing laser power density allowed to obtain dense material with fine structure. Further modifications of the process, such as overlapping tracks and/or changing traverse speed of laser beam, are to be investigated.

The examination of cross-section (perpendicular to tracks) of a representative Inconel 625 - $30 \mathrm{wt} \%$ WC sample (Fig. 4) showed that microstructures of coating were different depending on the distance from surface. Fig. 4A showed perpendicular cross-section of whole Inconel 625 - WC coating. Evolution of microstructure during deposition of layers can be seen. Heat affected zones were clearly observed. It showed how laser beam affected the deposited material. Interface area between coating and substrate was affected by heating, mostly during deposition of initial layers. As more layers were deposited, material was heated for a longer time which resulted in coarser dendrites. The near-surface areas were exposed for heat treatment for the longest time. Remelting which was performed to reduce roughness of surface, affected microstructure of the material. Largest grains appeared and a small number of vertically columnar dendrites was observed. Height of coating was about $1 \mathrm{~mm}$ for this sample.
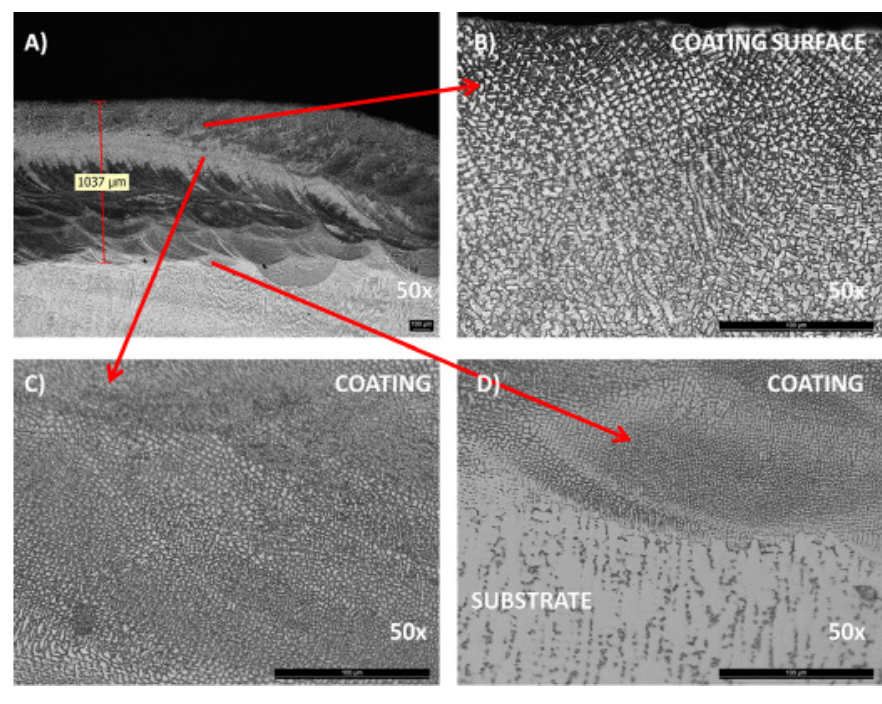

Fig. 4. Light Microscopy images showing Laser Cladded coating microstructure after etching in perpendicular to tracks cross section

Fig. 4B shows the area closest to surface of the coating. Fine structure of Inconel 625-WC composite was observed. Typical equiaxed dendrite sizes vary between 4 to $6 \mu \mathrm{m}$. In the deeper areas of the coating, appearance of columnar dendrites in vertical direction was observed. The vertical crystal growth was the result of temperature gradient in the direction of surface during laser cladding process [8].

As shown in Fig. 4C, the microstructure in the area inside the coating was different than near the coating surface. Dendrites had similar equiaxed shape but were much smaller. Typical measured sizes varied between 1 to $2.5 \mu \mathrm{m}$. This part of sample had no columnar dendrites due to high cooling rate. Growth of dendrites were prevented because of very rapid heating during deposition of deeper sublayers of coating. Heat affected zones can be observed as the meltpool proceed with laser beam.

Fig. 4D showed boundary between the deposited coating and substrate. The difference of microstructure is easily observed. The laser cladded Inconel 625-WC composite coating had fine structure. Grain size was smaller than grains closer to the coating surface. Typical measured size was under $1 \mu \mathrm{m}$. Shape of 
dendrites were exclusively equiaxed. In comparison, substrate material had long vertically columnar structure. Boundary between two structures showed good bonding. No cracks or pores appeared at the boundary [9].

Fine dendritic structure observed in Fig. 4, resulted from high cooling rate during the laser cladding process. Because of high energy density during laser beam interaction with substrate and powders, small spot was heated to a very high temperature. Due to good thermal conductivity of Inconel 625 above $600^{\circ} \mathrm{C}$ $-21.3 \mathrm{~W} / \mathrm{m} \cdot \mathrm{K}$ [25], heat provided by laser beam was instantly distributed around. High cooling rate allowed for rapid solidification which prevented growth of grains. This resulted in equiaxed shape of most dendrites [6].

\subsubsection{SEM and EDS}

Fig. 5A shows SEM image of the Inconel 625 reference coating. Two different phases were observed. Phase A (light gray after etching) appeared locally between phase B (dark gray after etching) grains. Phase A did not completely surround phase B grains. EDS analysis showed that weight concentration of carbon and chromium was similar for both phases. However, niobium concentration was higher in the phase $\mathrm{A}-8$ to $4 \mathrm{wt} \%$, while more nickel was located in the phase B -59 to $54 \mathrm{wt} \%$. Black pores appeared in microstructure.
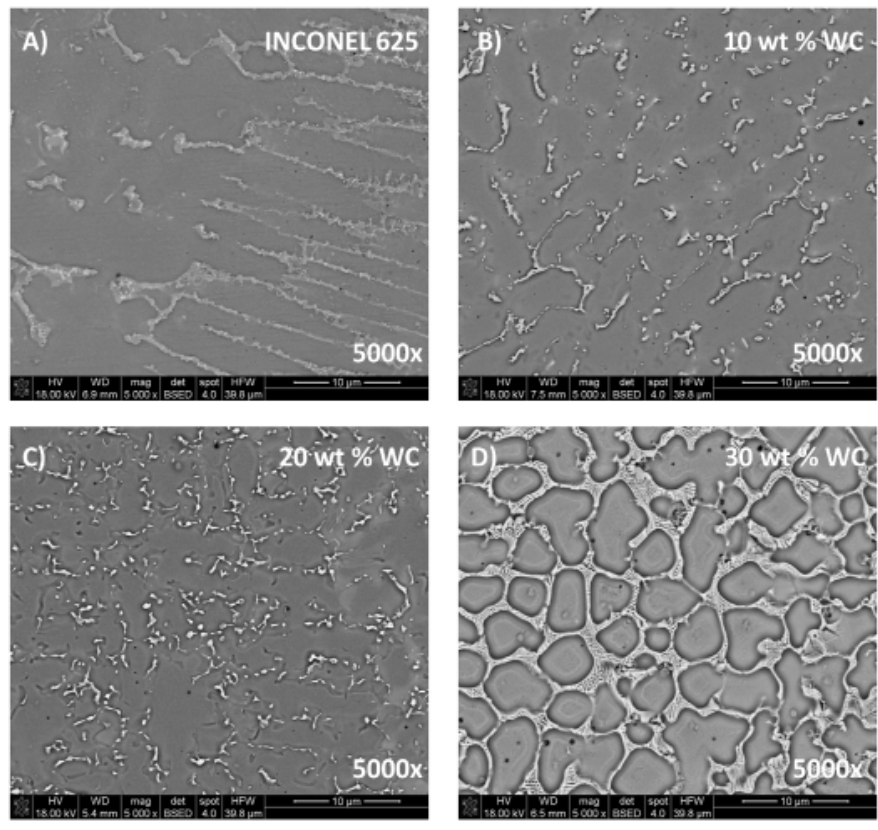

Fig. 5. SEM images of all deposited coatings; phase A (eutectic) seen as light gray; phase B (Inconel 625) seen as dark gray

As shown in Fig. 5B, laser coatings containing $10 \mathrm{wt} \%$ of WC were characterized by much finer structure than Inconel 625 reference sample. Dark phase B grains were slightly smaller. Phase A concentrated between grains of phase B. In some areas phase A started to form thin film on grain boundaries. Concentration of nickel, tungsten and chromium in phase A was much lower than in phase B. On the other hand, phase A contain extremely high amount of Niobium - $26 \mathrm{wt} \%$, in comparison to phase B $-2 \mathrm{wt} \%$. Similarly to reference sample, small amount of fine pores were observed.

Observation of Inconel 625 - 20 wt \% WC samples (Fig. 5C) showed higher amount of phase A. It locally formed large amount of thin film between darker phase B grains. Phase A contains less nickel and tungsten in comparison to the phase $\mathrm{B}$. Amounts of chromium and carbon were similar for them both. Two times more niobium was detected in phase A. Some porosity was observed in this sample. Phase B grains were observed, smaller than in previous samples.

Coating of Inconel 625 - $30 \mathrm{wt} \%$ of $\mathrm{WC}$, is shown in Fig. 5D. Observation of microstructure showed that darker phase $\mathrm{B}$ grains were completely surrounded by phase A. Phase A, containing larger amount of niobium - $10 \mathrm{wt} \%$, and carbon 3 wt $\%$, than phase B, had typical lamellar eutectic structure. Concentrations of tungsten and chromium were similar for both phases, while niobium was higher for the phase B. Small amounts of pores were observed.

SEM images with EDS point analysis showed differences between pure Inconel 625 and Inconel 625-WC coatings (Fig. 5). In pure Inconel 625 thin film of phase A was able to appear on grain surface due to the segregation of elements during supercooling [8]. Based on previous experiments of DuPont [10], crystallization of Inconel 625 welds proceeds with the following scheme: $\mathrm{L} \rightarrow \gamma \rightarrow \mathrm{L}+\gamma \rightarrow \mathrm{L}+\gamma+$ Laves $\rightarrow \gamma+$ Laves in temperature about $1200^{\circ} \mathrm{C}$ (where $\mathrm{L}-$ liquid, $\gamma$-gamma phase, Laves - Laves phases). Phases formed from elements which shows tendency to segregation in interdendritic areas, appears at the end of solidification process. It was found that appearance of various metal carbides in Inconel 625 welds is possible, because of eutectic reaction during supercooling of the material. As mentioned before, as a result of solidification of weld overlays, concentration of Mo and $\mathrm{W}$ in alloy increases. It leads to formation of TCP (topologically close-packed) phases, observed in Fig. 5D. In Inconel 625 carbides like $\mathrm{MC}, \mathrm{M}_{2} \mathrm{C}$, $\mathrm{M}_{6} \mathrm{C}$ and $\mathrm{M}_{23} \mathrm{C}_{6}$ are very likely to appear at higher temperatures from 870 to $1040^{\circ} \mathrm{C}$ [11]. However, the amount of phase A was small when compared to sample containing $30 \mathrm{wt} \%$ of WC. In this sample the eutectic phase which contained high amount of niobium and carbon was clearly seen as white lamellar structure surrounding darker phase B grains. Area inside phase B - Inconel 625 grains, contained increased amount of carbon and tungsten in comparison to pure Inconel 625. WC grains could not be observed by SEM. Because of their small size and good wettability by nickel, WC grains dissolved in Inconel 625 during laser action. During solidification, eutectic reaction occurred. Formation of eutectic was similar in whole samples. XRD analysis were needed to identify compounds present in obtained material. Final properties of Inconel 625 - WC coatings could depend on initial powder particle sizes. Bigger grains of $\mathrm{WC}$ are expected to not fully dissolve. In result, eutectic amount should be lower. 

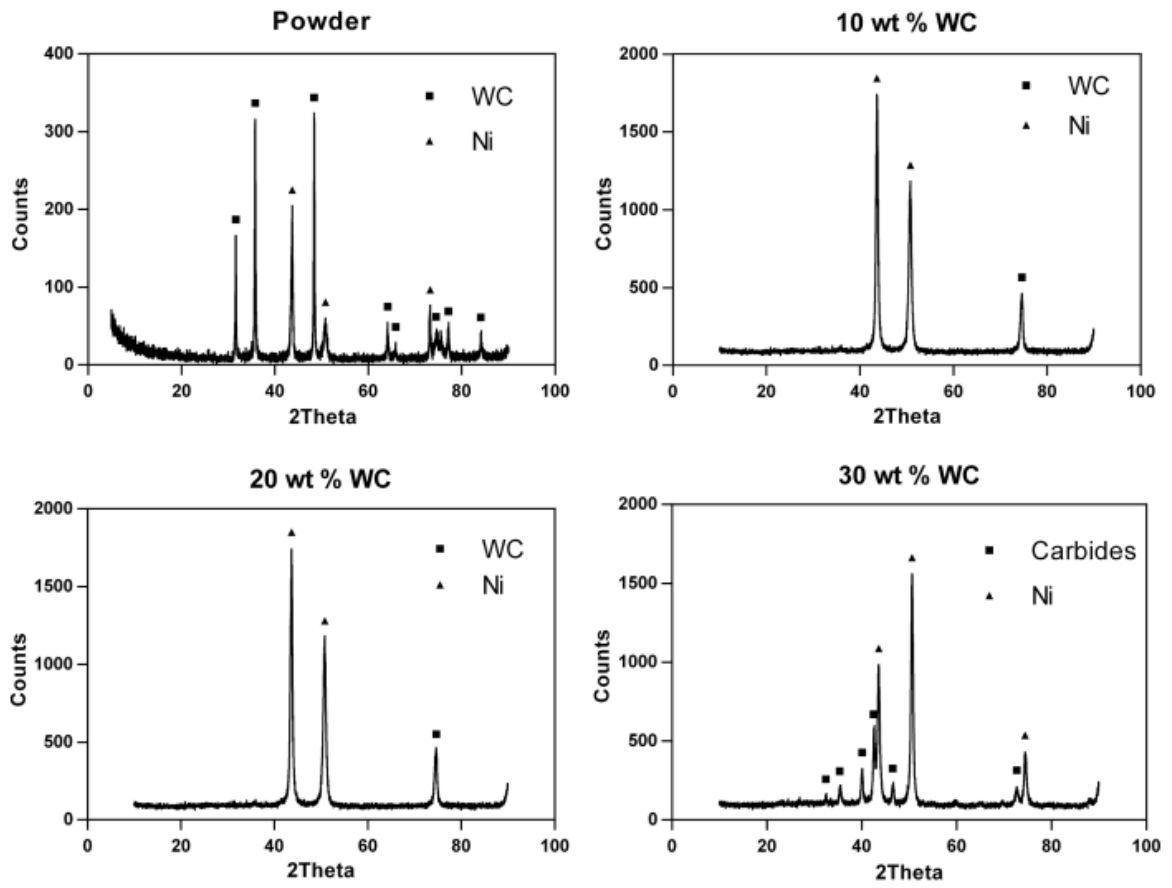

Fig. 6. XRD analysis of representative powder mixture and coatings: Powder, $10 \mathrm{wt} \% \mathrm{WC}, 20 \mathrm{wt} \% \mathrm{WC}-$ only $\gamma$-Ni and WC detected; $30 \mathrm{wt}$ $\% \mathrm{WC}-\gamma-\mathrm{Ni}$ and various carbides $\mathrm{WC}, \mathrm{W}_{2} \mathrm{C}, \mathrm{NbC},(\mathrm{NbW}) \mathrm{C}, \mathrm{W}_{6} \mathrm{C}_{2.54}$ and $(\mathrm{W}, \mathrm{Cr}, \mathrm{Ni})_{23} \mathrm{C}_{6}$ detected

\subsubsection{XRD}

The results of XRD analysis of powders mixtures and samples were presented in (Fig. 6). All of powder mixtures showed similar phase composition of nickel and tungsten carbide as presented on representative difractogram. Amount of detected WC vary from 33.2 vol. \% to 75.6 vol. \% depending on a sample. High amount of detected WC is the result of Inconel 625 grains which were covered in tungsten carbide particles.

The analysis of laser cladded coatings showed presence of WC. Samples containing 10 and 20 wt. \% of WC shows similar phase composition. Sample containing $10 \mathrm{wt}$ \% WC before laser cladding process contained $99.6 \mathrm{vol} . \%$ of nickel and $0.4 \mathrm{vol} . \%$ of WC, while 20 wt. \% WC sample contained $99.1 \%$ vol. of nickel and 0.9 vol. \% of WC. Detected tungsten carbide had typical hexagonal crystal structure. Small amount of WC is caused by its dissolution in Inconel 625 during laser action.

Phase composition of $30 \mathrm{wt}$ \% WC sample was different than previous samples. XRD analysis allowed to detect various carbides which signals were overlapping. Based on previous experiments [12] it was found that detected carbides were: $\mathrm{WC}$, $\mathrm{W}_{2} \mathrm{C}, \mathrm{NbC},(\mathrm{NbW}) \mathrm{C}, \mathrm{W}_{6} \mathrm{C}_{2.54}$ and $(\mathrm{W}, \mathrm{Cr}, \mathrm{Ni})_{23} \mathrm{C}_{6}$. The variety of different compounds was the result of WC dissolution in Inconel 625 matrix. This sample contained 83.6 vol. \% of Ni and 16.7 vol. \% of carbides.

Because of very small particle size and high temperature during laser cladding process, $\mathrm{WC}$ tends to dissolve in the Inconel 625. After recrystallisation it can form various kind of intermetallic phases, such as carbides, with other elements present in that alloy. This leads to formation of eutectic in the between Inconel 625 particles which is presented in Fig. 5D as phase A with fishbone - like structure. Because of high niobium concentration in Inconel 625, niobium carbide - $\mathrm{NbC}$ and Niobium tungsten carbide $-(\mathrm{NbW}) \mathrm{C}$ appeared. Because of overlapping signals, the exact amount of intermetallic compounds was difficult to identify by XRD analysis.

\subsubsection{Hardness}

Hardness tests performed on each sample showed that morphology of imprint left by Vickers intender was the same for each measurement. They were performed by making four series of tests beginning from surface of the sample, through the bulk to the boundary between coating and substrate as presented in Fig. 7.

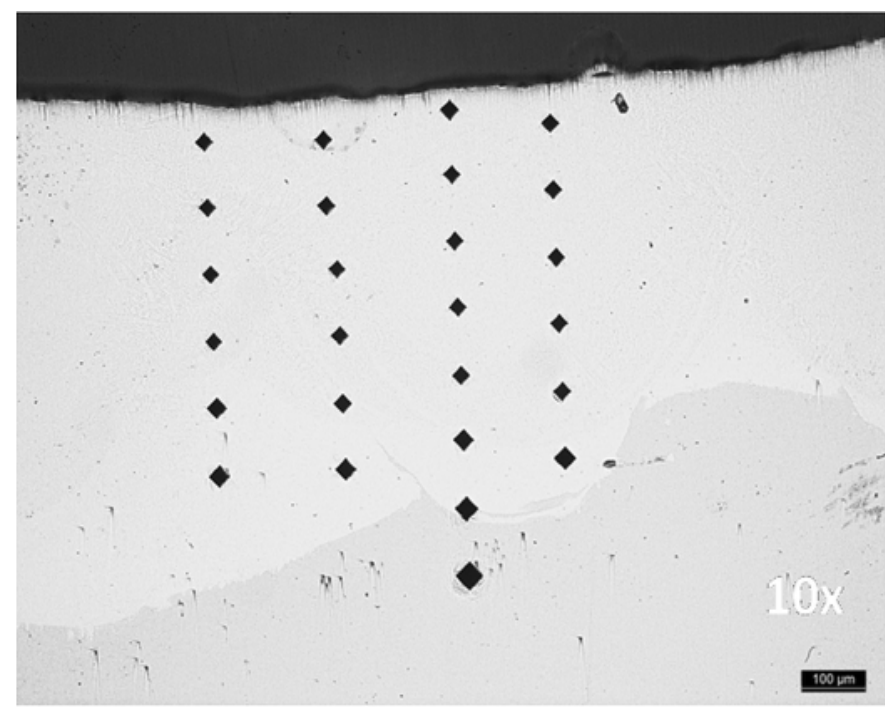

Fig. 7. Vickers Hardness - morphology of imprint was stable 
Results have shown that hardness of all laser cladded samples is higher than pure Inconel 625 substrate made by CMT. Results have shown that addition of 10 and $20 \mathrm{wt} . \%$ of fine WC powder to Inconel 625 had statistically insignificant effect on hardness (Fig. 8). Higher amount of fine tungsten carbide in 30 wt. \% sample caused Inconel 625 grains to be surrounded the eutectic in contrary to other samples. Formation of hard eutectic between Inconel 625 grains leads to significant improvement in hardness, from $396.3 \pm 10.5 \mathrm{HV}$ to $469.9 \pm 24.9 \mathrm{HV}$. As seen on the graph (Fig. 8) hardness of the material was changing with the distance from the surface. Subsurface layer is characterized by slightly lower hardness than deeper parts of the coating. This was probably the result of oxidation of surface material and of a different microstructure. Hardness measured in areas deeper inside samples was gradually decreasing to closer to the substrate. Nanohardness test was performed using diamond Berkovich nanoindenter to measure hardness of phase A - eutectic and phase B - Inconel 625 core. Core material had average hardness of $306.2 \mathrm{HV}$ which is much lower than hardness of eutectic $=534.2 \mathrm{HV}$. This confirms that eutectic mostly contains ceramic. Average hardness for each material are in Table 4.

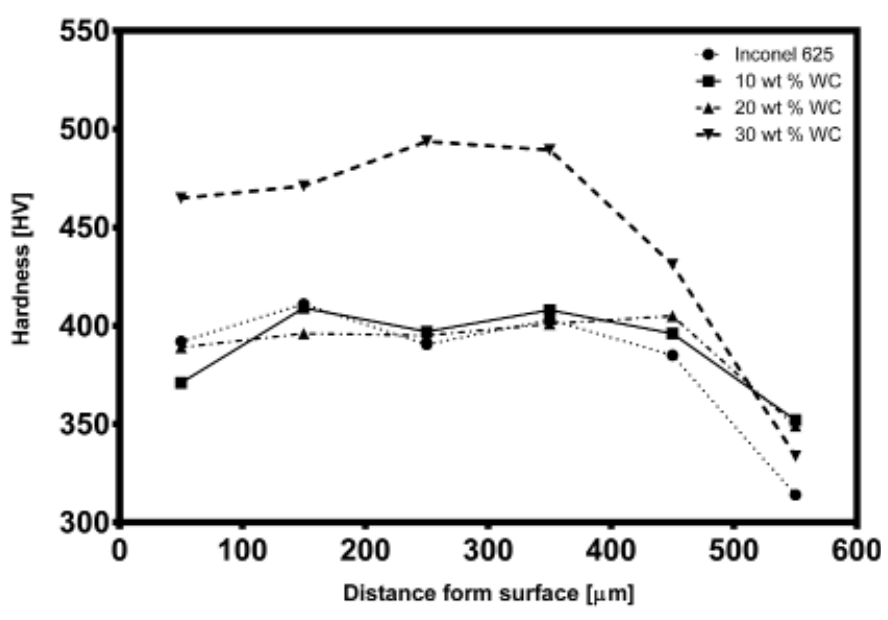

Fig. 8. Vickers Hardness vs distance from surface

TABLE 4

Average hardness of obtained materials

\begin{tabular}{|c|c|}
\hline Material & Hardness [HV] \\
\hline Inconel 625 - reference & $396.3 \pm 10.5$ \\
\hline Inconel 625 - 10 wt. \% WC & $396.2 \pm 15.3$ \\
\hline Inconel 625 - 20 wt. \% WC & $397.2 \pm 6.1$ \\
\hline Inconel 625 - 30 wt. \% WC & $469.9 \pm 24.9$ \\
\hline Phase A - eutectic & $534.2 \pm 34.4$ \\
\hline Phase B - Inconel 625 core & $306.2 \pm 31.08$ \\
\hline
\end{tabular}

\section{Conclusions}

From the presented results, it can be concluded that:

- $\quad$ Laser cladding of Inconel 625 - WC allows to obtain uniform, crack and pore-free coatings with very strong bonding to the substrate material.
- Controlling process parameters during laser cladding allows modification of material properties.

- High cooling rate (supercooling) during laser cladding process allows to obtain coatings characterized by fine, uniform structure.

- $\quad$ Fine WC powder dissolves in Inconel 625 during laser cladding process. When amount of $\mathrm{WC}$ is higher $-30 \mathrm{wt} \%$, it results in formation of fishbone-like eutectic TCP phase which contains various carbides $\left(\mathrm{WC}, \mathrm{W}_{2} \mathrm{C}, \mathrm{NbC},(\mathrm{NbW}) \mathrm{C}\right.$, $\mathrm{W}_{6} \mathrm{C}_{2.54}$ and $\left.(\mathrm{W}, \mathrm{Cr}, \mathrm{Ni})_{23} \mathrm{C}_{6}\right)$ It appears in the intergranular space.

- Despite differences in dendrite shapes and sizes, distribution of elements: $\mathrm{W}, \mathrm{C}, \mathrm{Nb}, \mathrm{Mo}, \mathrm{Cr}$ is similar in whole volume of samples.

- Small addition (10 and 20 wt. \%) of fine $\mathrm{WC}-0.54 \mu \mathrm{m}$, changes hardness insignificantly in comparison to pure Inconel 625 . Higher addition of WC - over 30 wt. \%, results in formation of hard eutectic surrounding Inconel 625 grains. This results in hardness improved from $396.3 \pm 10.5 \mathrm{HV}$ to $469.9 \pm 24.9 \mathrm{HV}$.

- Changing sizes of particles in substrate powders of Inconel 625 and WC could have effect on final properties of coatings. Bigger WC particles should not fully dissolve, this would have effect on amount of eutectic in material.

\section{Acknowledgements}

This work was performed within the framework of funding for statutory activities of AGH University of Science and Technology in Cracow, Faculty of Materials Science and Ceramics (11.11.160.617).

\section{REFERENCES}

[1] S.S. Sandhu, A.S. Shahi, Journal of Materials Processing Technology 233, 1-8 (2016).

[2] P. Ganesh, R. Kaul, C.P. Paul, P. Tiwari, S.K. Rai, R.C. Prasad, L.M. Kukreja, Materials Science and Engineering A 527, 74907497 (2010).

[3] S. Zhou, Y. Huang, X. Zeng, Q. Hu, Materials Science and Engineering A 480, 564-572 (2008).

[4] S. Zhou, Y. Huang, X. Zeng, Applied Surface Science 254, 31103119 (2008).

[5] F. Xu, Y. Lv, Y. Liu, F. Shu, P. He, B. Xu, Journal of Material Science and Technology 29 (5), 480-488, (2013).

[6] G.P. Dinda, A.K. Dasgupta, J. Mazumder, Materials Science and Engineering A 509 (1-2), 98-104 (2009).

[7] J. Kusiński, M. Blicharski, Ł. Cieniek, S. Dymek, M. Rozmus-Górnikowska, Inżynieria Materiałowa XXXVI (6), 363-367 (2015).

[8] M. Rombouts, G. Maes, M. Mertens, Journal of Laser Applications 24 (5) (2012).

[9] S. Zhou, X. Dai, X. Zeng, Applied Surface Science 255 (20), 8494-8500 (2009). 
[10] J.N. DuPont, Metallurgical and Materials Transactions Archives A 27, 2612-3620 (1996).

[11] T.E. Abioye, J. Folkes, A.T. Clare, D.G. McCartney, Journal of Surface Engineering 29 (9), 647-653 (2013).

[12] S. Zhou, Y. Huang, X. Zeng, Q. Hu, Materials Science and Engineering A 480, 564-572 (2008).

[13] K. Matsuura, T. Koyanagi, T. Ohmi, M. Kudoh, Materials Transactions 44 (5), 861-865 (2003).

[14] T.I. Khan, S.A. Rizvi, K. Matsuura, Wear 244, 154-164 (2000)

[15] N. Mizuta, K. Matsuura, S. Kirihara, Y. Miyamoto, Materials Science and Engineering A 492, 199-204 (2008).

[16] T.E. Abioye, A.T. Clare, D.G. McCartney, Journal of Materials Processing Technology 217, 232-240 (2015).

[17] M. Donachie, J. Donachie, Superalloys. A Technical Guide, ASM International, USA, 2-22 (2002).

[18] T. Sims, N.S. Stoloff, W.C. Hagel, Superalloys II: High-temperature materials for aerospace and industrial power, Wiley (1987).
[19] C. Leyens, E. Beyer, J. Lawrence (Ed.) Laser Surface Engineering Processes and Applications: Chaper 8 Innovations in laser cladding and direct laser metal deposition, Woodhead Publishing Series in Electronic and Optical Materials 65, 181-191 (2015).

[20] L. Costa, R. Vilar, Rapid Prototyping Journal 15 (4), 264-279 (2009).

[21] R.A. Ganeev, Laser-Surface Interactions, Springer Netherlands (2014).

[22] A.J. Antończak, Wybrane Zagadnienia z Laserowej Modyfikacji Materiałów, Oficyna Wydawnicza Politechniki Wrocławskiej, Wrocław (2014).

[23] J. Kusiński, Lasery i ich zastosowanie w Inżynierii Materiałowej, Wydawnictwo Naukowe Akapit (2000).

[24] Inconel 625 Specification [cited 20 June 2016]: http://www. alloywire.com/inconel alloy $625 . \mathrm{html}$

[25] Inconel 625 properties specification [cited 20 June 2016]: http:// www.hightempmetals.com/techdata/hitempInconel625data.php 